\title{
MEDICAL EDUCATION IN BRITAIN
}

$\mathrm{T}$ HE terms of the Rock Carling Fellowship, which was founded by the Governing Trustees of the Nuffield Provincial Hospitals Trust, provide that the holder shall make a review, by way of a monograph, of one of the fields in which Sir Ernest Rock Carling had been interested. Medical education was one of these, and in the preface to his monograph*, Prof. R. Milnes Walker, emeritus professor of surgery in the University of Bristol, mentioned some of Sir Ernest's activities in this field.

The establishment of a university degree as the only legal qualification to practise medicine was introduced in England as long ago as 1421. During the subsequent centuries, other means of obtaining the right to practise were permitted. For a time, only a minority of doctors held university degrees, and even up to 1938 less than half the medical students obtained degrees; to-day all doctors obtain admission to the Medical Register by a university degree.

The major steps in the evolution of medical education in Britain were the Apothecaries Act of 1815 and the Medical Act of 1858. In the interval between these dates the customary way into medical practice in England was by taking the Membership of the Royal College of Surgeons as a qualification in surgery, and the Licence of the Society of Apothecaries as a qualification in medicine. For those who aspired to Membership of the Royal College of Physicians, for which a university degree was necessary, it was customary to go to Scotland or to the Continent, where a doctorate in medicine was easier to obtain than at Oxford or Cambridge.

The impact of Abraham Flexner's survey of medical education in Europe in 1912 and his further investigation of medical education in general, published in 1925, cannot be exaggerated. It is to be regretted that Britain was so long in heeding his advice.

Many of the recommendations of the Goodenough Committee have now been implemented, however, and they were, in the main, adopted in establishing the relationships between the medical schools and the teaching hospitals when the National Health Service was brought into effect in 1948. Its report made no recommendations about medical man-power but, in an appendix, the Government Actuary estimated that if the number of practising British doctors were to be increased from the then figure of 45,400 to 55,000 in 15 years' time, the medical school entry would have to be raised from the prewar figure of 1,800 to 2,630. This allowed for a net emigration of only one in every nine doctors. The Committee considered that the increase should be brought about by raising the existing schools to their full capacity before embarking on the establishment of new schools, but it criticized the concentration of medical schools in London and the relatively excessive number of students in the Scottish schools.

Owing to the slow rate of hospital building since the introduction of the National Health Service, the facilities for elinical teaching which the Committee recommended have fallen short of the mark. Their recommendations regarding staffing of pre-clinical and clinical departments have, however, been implemented to a considerable extent. Almost every school now has full-time professors in general medicine and in general surgery, and obstetrics is moving fairly fast in the same direction. Some departments are still deplorably housed and, where this affects

*Medical Education in Britain. Pp. 101. (London: The Nuffield Provincial Hospitals Trust, 1965.) $5 s$. pathology and the clinical departments, this has in part been held up by the scarcity of new hospital building. No unit in an undergraduate school in Britain has the control of 100 beds, which was suggested in the Haldane Report as long ago as 1913.

Much progress has been made in implementing the proposal of the Goodenough Committee for the teaching of social medicine, child health and psychiatry, but the maternity training is often unsatisfactory in that students may have to make use of facilities far removed from their teaching hospitals.

The compulsory pre-registration hospital appointments for twelve months were introduced in 1954 and have become an accepted part of the British educational and hospital structure, but the suggested reduction of the undergraduate course to 4.5 years has not come about. That Britain is still short of its needs in medical education has been emphasized in many places, but particularly in the Review of the Medical Services in Great Britain, which. was published in 1963.

Prof. Milnes Walker referred to some of the changing aspects of medical practice which must influence medical education. In Britain, the increasing average age of the population raises problems as the elderly require an extra share of medical attention. It is wrong to assume that the Welfare State, with its better standards of living, will reduce the demand for medical care. When people have greater means they demand a better standard of medical attention, but they tend to be less inclined to look after their sick relatives at home, and, in fact, conditions often make this quite impossible. So the demand, and the cost, of a National Health Service continue to rise, and as it is unable to meet the demand an increasing number of people take out insurance to cover the cost of private medical attention outside the State Service.

The other important factor is the increased body of medical knowledge, which inevitably leads to increasing specialization. This widens the gap between general practitioners and specialists, and even among specialists themselves. The provision of group practices working from adequately staffed premises would lead to greater efficiency, and provide some means of improving the association between general practitioners and specialists.

Britain is going to be extremely short of doctors. Until recently, there has been one for every 930 of the population, but present figures indicate that there will be a proportion of one to 1,100 in a few years. This figure can be compared with one in about 600 in some European countries, and puts the ratio below that of Australia, Canada and the United States. Doctors are leaving Britain permanently at the rate of 400 a year, and this figure may well rise unless conditions in the Health Service are radically altered. It is important that enough doctors be trained for home needs and for emigration. An annual intake into medical education of about 3,500 , which is almost a 50 per cent increase on the present number, should be the ideal.

In discussing courses and syllabuses, Prof. Milnes Walker advises the abolition of the First M.B. examinations; the medical schools would cease to teach the pre-medical subjects in their present form to medical students.

The pre-clinical course should be increased to 2.5 years, or 3 years if a science degree is taken, but provided there was a second year of pre-registration appointments, the clinical period could be reduced to 2 years. 
Of tho 2 years of compulsory pre-rcgistration appointments, the second year nood not be one of residence in hospital, and, for many students, part of it should bo spent in general practice, approved for the purpose and working from a health contre.

The aim should be to increase the intake of modical students to 3,500 a year as quickly as possible. Preclinical schools could bo oxpanded to an intake of up to 200 , but clinical schools should not normally have an intake of more than 100. Thus, more clinical schools would be required, and at present there are suitable hospitals in some of our provincial cities with modical schools which could be adapted as second clinical schools without great expense, and would share the university departments. The number of pre-clinical schools in London could thus be reduced.
In teaching hospitals the distinetion between goneral medical and surgical wards should be abolished, but the teams in charge would comprise both physicians and surgeons, and the leaders of the teams might belong to oither discipline.

In postgraduate training the increase in the organized teaching in district hospitals is welcome, and will need further expansion if a second pre-registration year is introduced. In London another look should be taken at the grouping of tho spocial hospitals and institutes and some of them might be associated with or even incorporated in general hospitals.

For the better organization of postgraduate training of overseas doctors, an increase in the contacts with these countries and their medical schools is desirable, and regional boards might play a part in this.

\section{SYMMETRY PRINCIPLES AT HIGH ENERGY}

$I^{N}$ $\mathrm{N}$ so rapidly developing a subject as elementary particle physics frequent conferences play an important part in the exchange of knowledge. The doyen of such meetings is the 'Rochester' Conference, affectionately called after its place of origin even though to-day its meetings are as likely to be held in Geneva or Dubna. It is a gathering of several hundred theorists and experimenters, and when it comos together every two years its sessions are concerned with all aspects of the subject. A necossary complement to so large and infrequent an assembly is the holding of regular small conferences on specific topics. The Coral Gables Conferences on Symmetry Principles, organized by the Center for Theoretical Studies of the University of Miami, have come to occupy an honourable place among such meetings.

The first two Conforences were held during a hectic and euphoric time for the practitioners of symmetry principles: the rapid discovery by experimentalists of moro and more particles was matched by the invention by theorists of higher and higher symmetries with more extensive multiplets in which to locate them. Such boom conditions could not last for ever and if the atmosphere at the third Conference in January 1966 was less feverish this simply reflected a return to normal after the heady days of the immediate past. There were, nevertheless, many contributions of sober interest.

One of the most powerful techniques in symmetry physies has been the use of the current algebras invented several years ago by Gell-Mann and exploited by him to give many results in agreement with experiment. The method takes as its basic assumption the equal-time commutation relations of the integrated components of certain currents associated with weak, electromagnetic, and (by means of another assumption called the partially conserved axial current) strong interactions. During the past year Fubini and Furlan devised an important way of using dispersion theory in these calculations and this was employed by Adler and Weisberger to calculate the ratio of the Fermi coupling to Gamow-Teller coupling in $\beta$-decay, in excellent agreement with experimont. However, a useful assumption in many calculations, namely, that the commutation relations aro saturated by a small number of neighbouring states, encountered certain theoretical difficulties which were pointed out by Coloman. In his address to the Conference, Gell-Mann explained how these difficulties could be avoided by working with matrix elements of states corresponding to infinite momentum and using only that sub-algebra of currents which has finito matrix elements to states of finite mass in this limit. It is known that the octet and decimet baryons of $S U(3)$ do not saturate those relations. Gell-Mann and Dashen are engaged on a calculation using various low- energy experimentally determined parameters as the input by which they hope to determine what further states are needed for saturation and so to arrive at a prediction of the nature of the higher-lying baryon resonances.

The current algebra technique does not commit its user's to the belief that the algebra involved is a symmetry of the Hamiltonian applying to the whole of physics. It is only necessarily relevant for the matrix elements of the particular currents involved. Current algebras are thus essentially statements about the dynamical workings of the theory rather than about general invariance requirements. The relation between broken symmetries and dynamics is one that is little understood. Many people believe that the answer lies in a bootstrap theory which pictures elementary particles as all being bound states of each other, held together by forces due to the exchange of the particles themselves. In this way no particle is more elementary than any other and they can all be regarded as being composite. Simple models suggest that such theories might lead to symmetries, and Capps presented a contribution at the Conference on this question. However, realistic dynamical calculations are extremely difficult, not lcast because of a lack of understanding of the effect of multiparticle states on the structure of the theory.

The second Coral Gables Conference had heralded the entry of non-compact groups into elementary particle physics by the construction of relativistic versions of $S U(6)$. The unitary representations of these groups, which are needed in quantum mechanics, are infinitedimensional and considerable ingenuity was expended in breaking the symmetry in elegant ways so that finite multiplets corresponding to sets of elemontary particles could be obtained. However, ever since hole theory, elementary particle physicists have enjoyed making a virtue of vice, so that increasing numbers of people have thought that the presumably infinite sets of all elementary bosons and fermions, discovered and yet to come, might correspond to two or more infinite-dimensional repre. sentations of a non-compact group. This idea of killing infinitely many birds with one stone gained some encouragcment from the fact which had long been known that the bound states of the hydrogen atom correspond to a single representation of $O(4,1)$. Fronsdal and Rühl gave details of some investigations they had made along these lines. Some initial difficulties in the satisfactory coupling of representations have been overcome and an unexpected feature is that the Born approximation already gives nontrivial momentum-dependent form factors. Another worker in this fiold is Salam, and his absence from the Conference owing to illness was much regretted both for 